\title{
BMJ Open Profile, cost and pattern of prescriptions for polymedicated patients in Catalonia, Spain
}

\author{
Irene Lizano-Díez, ${ }^{1}$ Pilar Modamio, ${ }^{1}$ Pilar López-Calahorra, ${ }^{2}$ Cecilia F Lastra, ${ }^{1}$ \\ Antoni Gilabert-Perramon, ${ }^{2}$ Jose L Segú, ${ }^{1}$ Eduardo L Mariño ${ }^{1}$
}

To cite: Lizano-Díez I, Modamio P, LópezCalahorra $\mathrm{P}$, et al. Profile, cost and pattern of prescriptions for polymedicated patients in Catalonia, Spain. BMJ Open 2013;3:e003963. doi:10.1136/bmjopen-2013003963

- Prepublication history and additional material for this paper is available online. To view these files please visit the journal online (http://dx.doi.org/10.1136/ bmjopen-2013-003963).

Received 5 September 2013 Revised 5 November 2013 Accepted 7 November 2013

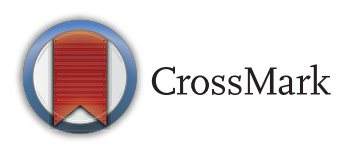

${ }^{1}$ Clinical Pharmacy and Pharmacotherapy Unit, Department of Pharmacy and Pharmaceutical Technology, Faculty of Pharmacy, University of Barcelona, Barcelona, Spain ${ }^{2}$ Department of Pharmaceutical Care and Complementary Benefits, Catalan Health Service, Government of Catalonia, Barcelona, Spain

\section{Correspondence to} Eduardo L Mariño; emarino@ub.edu

\section{ABSTRACT}

Objectives: Polypharmacy is one of the main management issues in public health policies because of its financial impact and the increasing number of people involved. The polymedicated population according to their demographic and therapeutic profile and the cost for the public healthcare system were characterised.

Design: Cross-sectional study.

Setting: Primary healthcare in Barcelona Health Region, Catalonia, Spain (5 105551 inhabitants registered).

Participants: All insured polymedicated patients. Polymedicated patients were those with a consumption of $\geq 16$ drugs/month.

Main outcomes measures: The study variables were related to age, gender and medication intake obtained from the 2008 census and records of prescriptions dispensed in pharmacies and charged to the public health system.

Results: There were 36880 polymedicated patients (women: $64.2 \%$; average age: $74.5 \pm 10.9$ years). The total number of prescriptions billed in 2008 was 2266830 (2 272920 total package units). The most polymedicated group (up to $40 \%$ of the total prescriptions) was patients between 75 and 84 years old. The average number of prescriptions billed monthly per patient was $32 \pm 2$, with an average cost of $€ 452.7 \pm 27.5$. The total cost of those prescriptions corresponded to $2 \%$ of the drug expenditure in Catalonia. The groups N, C, A, R and M represented $71.4 \%$ of the total number of drug package units dispensed to polymedicated patients. Great variability was found between the medication profiles of men and women, and between age groups; greater discrepancies were found in paediatric patients (5-14 years) and the elderly ( $\geq 65$ years).

Conclusions: This study provides essential information to take steps towards rational drug use and a structured approach in the polymedicated population in primary healthcare.

\section{INTRODUCTION}

Polymedication is becoming an increasingly important issue in public health policies and

\section{Strengths and limitations of this study}

- This study includes 1-year monitoring of a large sample size, and provides a way to examine drug use under real-life situations, linked to practice through the prescriber and also to the patient. This information is essential in order to take steps towards rational drug use and a structured approach in the polymedicated population.

- Administrative information systems are not perfect and could limit the measurement of data quality in electronic records.

- Information related to prescription rates and costs should be viewed cautiously, due to the different forms of presentation and costs of medicines in other countries.

it may have a negative impact on patients and the healthcare system. ${ }^{1}$ Among the reasons that contribute to the increase in polymedication are the ageing population, the prevalence of chronic diseases and the increased availability of drugs and access to healthcare services. ${ }^{2} 3$

In quantitative terms, polymedication is defined as various drugs taken simultaneously by the same user. ${ }^{4}$ Although there is no consensus on the number of drugs a patient must take to be classified as polymedicated, four or more seems to be the accepted figure in most cases. ${ }^{5}$ However, several studies suggest that the average number of drugs consumed daily by the elderly is $4.2-8,{ }^{6-8}$ with a maximum of 17 different drugs/day. ${ }^{7}$

In general, polymedication is more common among women, institutionalised patients and in rural areas, and is directly related to the number of prescribers. ${ }^{9-11}$ In addition, comorbidities increase with age and the number of drugs prescribed. ${ }^{12}{ }^{13}$ Hence, there is an increased risk of medicationrelated problems that can cause treatment failure, poisoning and an increased number of hospital admissions. ${ }^{513} 14$ 
At the very least, periodically reviewing the treatment regimen of polymedicated patients may prevent these several problems and help professionals rationalise the use of medication. ${ }^{11} 14 \quad 15$ Thus, implementing programmes to analyse and support polymedicated patients has become one of the priorities of the various national health services, ${ }^{16-20}$ including the Spanish National Health Service $^{14}$ and the regional health administrations of Spain. However, no studies to describe the pattern of consumption in Spain have been carried out till today.

A suitable setting for the consideration of the wide range of issues related to polypharmacy is the Barcelona Health Region (BHR). This region's population lives in both rural and urban areas and has access to various types of healthcare services. ${ }^{21}$ Thus, the objectives of this study were first to determine the number and prevalence of polymedicated patients receiving 16 or more medications in the public healthcare system in BHR, in order to describe the profile of polymedicated patients and identify their costs. Second, to describe the medications prescribed in the study population, differentiated by age and gender.

\section{METHODS}

\section{Design and setting of the study}

A cross-sectional observational study of all the insured polymedicated patients in 2008. The study was performed in the field of primary healthcare and, specifically, in BHR.

\section{Data source}

The study used population data from the 2008 Catalonia census. $^{22}$ According to the census, BHR had 5105551 registered inhabitants, 2604190 (51\% of the total) of whom were women, accounting for $68 \%$ of the total population of Catalonia. The age distribution of this region population showed predominance of adults (34\% of the population was between 25 and 44).

Records of billed prescriptions dispensed in pharmacies and charged to the Catalan Health Service were also utilised. This information was obtained by means of the personal healthcare card, the document that provides citizens with access to the centres, services and provisions of the public health system (these services include drugs subsidised by the Catalan Health Service). This information is stored monthly in a computer system, which allows the information required for the management and monitoring of pharmaceutical services to be designed and collected.

\section{Data collection and variables}

A polymedicated user in the present study was defined as someone receiving 16 or more active principles in a month. The control of the polymedicated population in Catalonia and each health region (number of users and drug consumption bill) following this criteria is part of the Efficiency Indicators in Primary Care, and is periodically evaluated by an internal Management Committee in the Catalan Health Service (macromanagement level). Concurrently, each health region team is also involved in limiting the polymedication approach to the needs and priorities for all indicators to be improved (micromanagement level). In case of BHR, and according to the 2008 objectives, this indicator was working at the level of each primary care team or capitation area, and referred to each provider. In such cases of high-risk polymedicated patients, a diagnostic justification was required by the BHR team.

The data collected from the profiles of the polymedicated patients were gender and age. Nine age groups were established (5-14, 15-24, 25-34, 35-44, 45-54, 55-64, 65-74, 75-84 and more than 84 years). In terms of drugs consumption, the following were identified: number of prescriptions billed, number of package units dispensed, total cost of medications dispensed and the amount financed by the Catalan Health Service (the total cost of medications dispensed minus the out-ofpocket amount paid by the patients). A package unit is defined as a standard package of a medication dispensed to a patient (prepared by the manufacturers), which does not necessarily coincide with the number of medication units required by the patient. A set of indicators was then obtained: the number of prescriptions per user, the number of package units dispensed per user, the total cost of drugs dispensed per user, the number of prescribers (that prescribed at least one drug) and the level of copayment by the patient at the time of dispensing in the pharmacy.

A descriptive study was conducted simultaneously on the types of drugs prescribed in order to characterise the general therapeutic profile of the study population (number of prescriptions and number of package units dispensed). The drugs were grouped based on the Anatomical-Therapeutic-Chemical Classification System. ${ }^{23}$

\section{Literature review}

A systematic search was conducted (April 2013) through database PubMed to identify the available evidence on the prevalence and medication profile of polymedicated users, as well as the cut-offs indicating multiple drug use. The terms to run the search were located by the vocabulary Medical Subject Headings, with which the articles are indexed in the MEDLINE database. In order to complete this search and extend the results, additional searches combining free terms were also conducted. All search strategies (7) resulted in 2188 references. The studies identified through this search were evaluated by two independent reviewers to assess their inclusion in this document.

\section{Data analysis}

A database was designed. Analysis of variance and Student $t$ tests were used to determine the statistical significance $(p<0.05)$ of the differences between population subgroups using the SPSS V.20.0 statistics program. 
Table 1 Polymedicated patients and the number of prescriptions in Barcelona Health Region (BHR) with their monthly changes in 2008

\begin{tabular}{|c|c|c|c|c|c|c|c|}
\hline \multirow[b]{2}{*}{ Month (2008) } & \multicolumn{3}{|l|}{ Users } & \multicolumn{3}{|c|}{ Monthly evolution (\% users) } & \multirow[b]{2}{*}{ Prescriptions billed } \\
\hline & Total & Men & Women & Total & Men & Women & \\
\hline January & 8160 & 2962 & 5198 & 31 & -7 & -7 & 251033 \\
\hline February & 7407 & 2659 & 4748 & -9 & -10 & -9 & 223772 \\
\hline March & 7029 & 2578 & 4451 & -5 & -3 & -6 & 212659 \\
\hline April & 8136 & 2864 & 5272 & 16 & 11 & 18 & 247206 \\
\hline May & 6470 & 2270 & 4200 & -20 & -21 & -20 & 192904 \\
\hline June & 5691 & 1995 & 3696 & -12 & -12 & -12 & 168492 \\
\hline July & 5553 & 1976 & 3577 & -2 & -1 & -3 & 186820 \\
\hline August & 4034 & 1437 & 2597 & -27 & -27 & -27 & 139117 \\
\hline September & 4396 & 1528 & 2868 & 9 & 6 & 10 & 150538 \\
\hline October & 5631 & 1986 & 3645 & 28 & 30 & 27 & 191498 \\
\hline November & 4762 & 1699 & 3063 & -15 & -14 & -16 & 155846 \\
\hline December & 4525 & 1635 & 2840 & -5 & -4 & -7 & 146945 \\
\hline
\end{tabular}

\section{RESULTS}

Description of the polymedicated patients

The number of polymedicated patients in BHR in 2008 was 36880 (0.72\% of the total population in BHR) and accounted for $78 \%$ of the polymedicated population of Catalonia in 2008; 1 of every 43 filling prescriptions met the criteria for polymedication in BHR. The monthly average of polymedicated patients with these characteristics was $5983 \pm 1448$. Table 1 shows the total number of polymedicated patients and the number of prescriptions with the 2008 monthly changes (increase or decrease) in BHR.

Table 2 shows the percentage distribution, by gender and age group, of the polymedicated population and the total population in BHR. The average age of the 36880 patients was $74.5 \pm 10.9$ years (the full range was 9-108 years) and more than two-thirds of them were women $(64.2 \%)$. It is noteworthy that $67 \%$ of the polymedicated patients were between 65 and 84 years. After individually analysing nine age groups, there appeared to be significant differences in the mean age between men and women in all age groups $(\mathrm{p}<0.05)$, except between 25 and 34, 45 and 54, 55 and 64 years.

\section{Indicators of drug consumption}

The total number of prescriptions for polymedicated patients billed to BHR in the year of study was 2266830 (2 272920 total package units; 2110290 were drug package units), and the average number of prescriptions dispensed per month was $182722 \pm 36991$. When these items were analysed by age group, the maximum number of prescriptions billed was by patients between 75 and 84 years, the most polymedicated group (up to $40 \%$ of the total prescriptions billed). In groups of patients older than 84 , the number of prescriptions decreased relevantly.

Overall, the average number of prescriptions billed monthly per patient was $32 \pm 2$, and the average cost per patient per month was $€ 452.7 \pm 27.5$. The number of prescriptions billed per patient increased with the age group (up to $45-54$ years). After examining the values for the different months, the average rate of increase

Table 2 Distribution of polymedicated patients and residents in Barcelona Health Region (BHR), by gender and age group

\begin{tabular}{|c|c|c|c|c|c|c|c|c|c|}
\hline \multirow[b]{2}{*}{ Age group (years) } & \multicolumn{3}{|c|}{ Users (\%) } & \multicolumn{3}{|c|}{ Population (\%) } & \multicolumn{3}{|c|}{ Difference (\%) } \\
\hline & Total & Men & Women & Total & Men & Women & Total & Men & Women \\
\hline $5-14$ & 0 & 0 & 0 & 9.8 & 5 & 4.7 & -9.8 & -5 & -4.7 \\
\hline $15-24$ & 0.1 & 0 & 0 & 10.2 & 5.2 & 5 & -10.1 & -5.2 & -5 \\
\hline $25-34$ & 0.2 & 0.1 & 0.2 & 17.5 & 9 & 8.5 & -17.3 & -8.9 & -8.3 \\
\hline $35-44$ & 1.1 & 0.4 & 0.7 & 16.6 & 8.5 & 8.1 & -15.5 & -8.1 & -7.4 \\
\hline $45-54$ & 3.3 & 1.2 & 2.1 & 13.1 & 6.4 & 6.7 & -9.8 & -5.2 & -4.6 \\
\hline $55-64$ & 11 & 4.2 & 6.8 & 11.1 & 5.3 & 5.8 & -0.1 & -1.1 & 1 \\
\hline $65-74$ & 27.1 & 10.4 & 16.7 & 8.1 & 3.7 & 4.4 & 19 & 6.7 & 12.3 \\
\hline $75-84$ & 39.9 & 14.4 & 25.5 & 6.1 & 2.4 & 3.7 & 33.8 & 12 & 21.8 \\
\hline$>84$ & 17.3 & 5.1 & 12.2 & 2.1 & 0.6 & 1.5 & 15.2 & 4.5 & 10.7 \\
\hline
\end{tabular}


in billed prescriptions between the age groups (up to $45-54$ years) was $9 \pm 12.3$ prescriptions per patient. However, in age groups above $45-54$ years, this rate of increase began to stabilise and started to decrease at a rate of $-3 \pm 1$ prescriptions billed per patient. The cost per patient followed this same pattern, but the cost started to decrease earlier, starting from the 35-44 age group at a rate of $€-70 \pm 29$ / patient.

The number of prescribers that issued at least one prescription varied each month depending on the age and gender of the patients. The monthly average was $3 \pm 2$ prescribers/patient/month, and $0.3 \%$ of patients were prescribed by 10 or more physicians/month. Elderly patients between 65 and $84 \quad(\mathrm{p}<0.05)$ and women $(p<0.05)$ made the greatest number of visits to healthcare professionals.

With regard to the copayment level applied to the patient at the time of dispensing, $95.5 \%$ of users were exempt from payment (retirees). In 2008, the Catalan Health Service funded $97 \%$ of the total cost of medications. BHR accounted for $69 \%$ of the drug expenditure in Catalonia; of this percentage, $2 \%$ corresponded to the total cost of prescriptions for polymedicated patients in the region.

\section{Descriptive analysis of medications prescribed for polymedicated patients}

The online supplementary appendix 1 shows the distribution of drug use by age groups among polymedicated patients in BHR. Since the range of prescription drugs was widespread, they were classified according to the main anatomical group and therapeutic subgroup to minimise variability and to improve the readability of the results. The five main groups $(\mathrm{N}, \mathrm{C}, \mathrm{A}, \mathrm{R}$ and $\mathrm{M}$ ) represented $71.4 \%$ of the total number of drug package units dispensed. Women followed the same pattern as above (group N 15.8\%; group C 13.2\%; group A $10.8 \%$ and group $\mathrm{R} 5.1 \%$ of the total drug package units dispensed). However, in men, group $\mathrm{C}$ drugs $(8.9 \%$ of the total drug package units dispensed) ranked first, followed by groups $\mathrm{N}$ and $\mathrm{A}$ (7\% and $5.9 \%$ of the total drug package units dispensed, respectively).

The monthly average of the various active principles dispensed to polymedicated patients in BHR was 1536 \pm 42 (peaking in February with 1599 through December with 1476). In general, women had a higher monthly average of prescriptions (different active principles; 799 \pm 22 ). The 25 most commonly used active principles by polymedicated men and women in BHR in 2008 represented about $40 \%$ of the total drug package units dispensed (40.3\% in women and $38.6 \%$ in men). The online supplementary appendix 2 shows the full set of results.

Some peculiarities were observed when determining the drugs most frequently prescribed for polymedicated patients; they were differentiated by age group, because the pathologies affecting each population are distinct. In children between 5 and 14 years, nearly $30 \%$ of the medications dispensed were losartan, paracetamol and omeprazole; losartan was the most frequently prescribed medication (9\% of all prescriptions in this age group). A change in the consumption patterns of polymedicated patients was observed starting from patients between the ages of 45 and 54, where the number of prescriptions for drugs such as metformin, enalapril, furosemide and aspirin progressively increased. Consumption of group $\mathrm{N}$ drugs in users between 65 and 74 years started decreasing to $21.7 \%$ of the total medication dispensed, whereas group $\mathrm{C}$ drugs started increasing $(22.8 \%$ of the medication dispensed), turning out to be the most dispensed drugs.

Significant differences were observed between the medication profiles of polymedicated men and women. In men, the two most commonly prescribed drugs were omeprazole and paracetamol, while in women the order was reversed. The most distinguishing feature between men and women was that some chemical subgroups were consumed more by one gender than the other. For example, respiratory drugs were predominant in men, as were antithrombotic agents and vasodilators for coronary disease, such as organic nitrates.

In general, polymedicated patients had a high consumption of anxiolytics, antidepressants, and hypnotics and sedatives, which correspond to $9.4 \%$ of the total drug package units dispensed $(4.4 \%, 3.4 \%$ and $1.6 \%$, respectively, for each group). Women, who represented $45 \%$ of the users of these drugs, simultaneously consumed these three groups of drugs in 2008. Specifically, $80 \%$ of women consumed anxiolytics, sedatives or hypnotics, while $61 \%$ consumed antidepressants. In contrast, the consumption among polymedicated men was $69 \%$ and $42 \%$, respectively, and concurrent use of all three groups of drugs was only $29 \%$.

\section{DISCUSSION}

The cut-off established in this study to determine the number of polymedicated patients in BHR is not commonly used in the published literature available. Regarding the number of active principles dispensed monthly $(\geq 16)$, as explained in methods, it is an operational indicator that gives rise to intervention and therefore prioritises that number to influence in that population with potentially greater risk. Besides, due to the volume of data and the subsequent processing and management in the health region, it is unfeasible to consider patients consuming less than this figure. As far as the outcome of consumption is concerned, the number of package units dispensed is the most used indicator by the Catalan Health Service to calculate the total pharmaceutical expenditure of this population and in consequence the impact on the public health budget of BHR.

After a literature review of 2188 references, only 12 of the studies which met the inclusion criteria considered a cut-off of 10 or more drugs, and only one of them followed a similar approach and criteria as ours (polypharmacy 
cut-off $\geq 15$ drugs).$^{24}$ In general, many patients receive prescriptions for a large number of drugs, both in our healthcare system and in that of other western countries. Obviously, this situation can be observed more commonly in elderly patients, who require special monitoring, revisions and adjustment of their prescribed medications, for both clinical and expenditure implications. ${ }^{1}$

This study was conducted in BHR due to its size $(68 \%$ of total population in Catalonia), density of population (1606 inhabitants $\left./ \mathrm{km}^{2}\right)$, extension $\left(3179 \mathrm{~km}^{2}\right)$ and subsequent high consumption of medicines observed. In addition, population distribution by age and gender is similar in both BHR and Catalonia. This region has the largest number of polymedicated patients in Catalonia, representing $78 \%$ of the total polymedicated patients in 2008. ${ }^{22}$ Data accumulated by the Catalan Health Service concerning polymedication issues show that the fluctuation in the number of prescriptions follows a seasonal pattern. ${ }^{25}$ Throughout the year the number of prescriptions increased in January, June and October, mainly due to visits to physicians before (June) and after (January and October) the holiday period. In addition, the increase in prescriptions in April was due to the annual review of the reference pricing system by the government, ${ }^{26}{ }^{27}$ which reduces the price of drugs from year to year. The new prices came into effect in May and therefore the turnover rate in pharmacies increased (and thus the number of patients and billed prescriptions) in the previous month.

According to published population studies, polymedicated patients are mostly women over 65 with multiple chronic diseases, frequent exacerbations and severe comorbidities, all of which imply a greater consumption of different medications and more frequent visits to health centres to collect prescriptions and/or consult physicians. ${ }^{10} 1728$ Younger and more elderly patients (5-14 and >84 years, respectively) are fewer in number and consume fewer medications with respect to the number of prescriptions and drugs dispensed. ${ }^{29}{ }^{30} \mathrm{In}$ contrast, some European studies, such as one by Linjakumpu et $a l^{10}$ in Finland, showed an increased medication consumption in patients over the age of 84 .

The data on drugs most commonly used by polymedicated patients in BHR describe their typical medication profile. However, there is great variability in the types of medications these patients consume and it is not minimised when drugs are classified by the therapeutic subgroup. Logically, the most specific classification, that is, classification by chemical substances, will further increase the variability of the medication profile. According to other studies on drug consumption among the general population, the main anatomical groups with the highest consumption are similar to this study $(\mathrm{N}, \mathrm{C}, \mathrm{A}, \mathrm{R}$ and $\mathrm{M}) .{ }^{31}$ In polymedicated patients, these five groups accounted for $71.4 \%$ of the total package units dispensed. Specifically, omeprazole and paracetamol were the two most frequently consumed drugs $(8 \%$ in men and $10 \%$ in women).
The study shows that consumption of antidepressants, hypnotics and sedatives, and anxiolytics, is a typical indicator of polymedicated patients and is especially significant among women, $45 \%$ of whom used at least two of these groups concurrently in 2008. The literature also indicates that the consumption of these drugs is higher among women and can be explained, among others, by their selfperceived poorer state of health and the high prevalence of mental illness and musculoskeletal problems. ${ }^{32-34}$

Despite the importance of polymedication, there is little information on the use of drugs in population subgroups. The majority of previous studies have focused on analysing expenditure by indirectly studying drug consumption based on the amount sold, population health surveys and home medication cabinets. ${ }^{35} 36$

Our study has several limitations. Administrative information systems are not perfect and could limit measurement of data quality in electronic records. This aspect should be taken into account when generalising our results. On the other hand, this study includes a large sample size and provides a way to examine drug use under real-life situations (linked to practice through the prescriber and also to the patient) that potentially increase generalisability. Besides, the information related to prescription rates and costs should be viewed cautiously, as, due to the different forms of presentation and costs of medicines, this information cannot easily be extrapolated to other countries. This would not be the case nationally, as medicines are standardised throughout the whole of Spain. In addition, we did not have access to clinical data, such as medical conditions to determine whether prescribing practices were clinically appropriate.

To conclude, this study provides results concerning the prevalence of polymedicated users in the public healthcare system in Catalonia and shows that the general profile is a woman over 65 with chronic diseases and comorbidities that involve a high consumption of different drugs and thus a higher cost to the healthcare system, in contrast to younger and more elderly patients. This information is essential in order to take steps towards rational drug use and a structured approach in the polymedicated population. These may be practices based and should take into account factors such as age, gender and clinical conditions.

Contributors IL-D collected the data, conducted the analysis and wrote the first draft of the manuscript. PM advised on design the study, data analysis and helped revise the draft of the manuscript. PL-C helped in conduct of study and data analysis. CFL helped data analysis and helped revise the draft of the manuscript. AG-P contributed to design the study and expertise in interpretation and analysis. JLS contributed expertise in interpretation and analysis and helped revise the draft manuscript. ELM contributed to design the study, contributed expertise in interpretation and analysis and helped revise the draft manuscript. All authors reviewed and agreed on the submitted version of the manuscript.

Funding This research received no specific grant from any funding agency in the public, commercial or not-for-profit sectors.

Competing interests None. 
Provenance and peer review Not commissioned; externally peer reviewed.

Data sharing statement No additional data are available.

Open Access This is an Open Access article distributed in accordance with the Creative Commons Attribution Non Commercial (CC BY-NC 3.0) license, which permits others to distribute, remix, adapt, build upon this work noncommercially, and license their derivative works on different terms, provided the original work is properly cited and the use is non-commercial. See: http:// creativecommons.org/licenses/by-nc/3.0/

\section{REFERENCES}

1. Payne RA, Avery AJ. Polypharmacy: one of the greatest prescribing challenges in general practice. Br J Gen Pract 2011;61:83-4.

2. Brager R, Sloand E. The spectrum of polypharmacy. Nurse Pract 2005;30:44-51.

3. Bushardt R, Massey EB, Simpson TW, et al. Polypharmacy: misleading, but manageable. Clin Interv Aging 2008;3:383-9.

4. Aronson JK. In defence of polypharmacy. Br J Clin Pharmacol 2004;57:119-20.

5. Bjerrum L, Rosholm JU, Hallas J, et al. Methods for estimating the occurrence of polypharmacy by means of a prescription database. Eur J Clin Pharmacol 1997:53:7-11.

6. Graves T, Hanlon JT, Schmader KE, et al. Adverse events after discontinuing medications in elderly outpatients. Arch Intern Med 1997;157:2205-10.

7. Hohl CM, Dankoff J, Colacone A, et al. Polypharmacy, adverse drugs and potential adverse drug interactions in elderly. Ann Emerg Med 2001;38:666-71.

8. Rollason V, Vot N. Reduction of polypharmacy in the elderly. A systematic review of the role of the pharmacist. Drugs Aging 2003;20:817-32.

9. Veehof L, Stewart R, Haaijer-Ruskamp F, et al. The development of polypharmacy. A longitudinal study. Fam Pract 2000;17:261-7.

10. Linjakumpu T, Hartikainen S, Klaukka T, et al. Use of medications and polypharmacy are increasing among the elderly. J Clin Epidemiol 2002;55:809-17.

11. Anthierens S, Tansens A, Petrovis M, et al. Qualitative insights into general practitioners views on polypharmacy. BMC Fam Pract 2010;11:65-71.

12. Denneboom W, Dautzenberg MGH, Grol R, et al. Analysis of polypharmacy in older patients in primary care using a multidisciplinary expert panel. Br J Gen Pract 2006;56:504-10.

13. Steinman MA. Polypharmacy and the balance of medication benefits and risks. Am J Geriatr Pharmacother 2007;5:314-16.

14. Programas de mejora en la atención a pacientes crónicos y polimedicados durante el año 2009 (Programs of improvement in the attention to chronic and polymedicated patients during the year 2009). Inf Ter Sist Nac Salud 2009;33:28. http://www.msc.es/en/ biblioPublic/publicaciones/recursos_propios/infMedic/docs/vol33_ 1nuevasIndAutorizadas2008.pdf (accessed 17 Dec 2012).

15. Aranaz-Andrés JM, Aibar C, Limón R, et al. A study of the prevalence of adverse events in primary healthcare in Spain. Eur $J$ Public Health 2012;22:921-5.

16. Haider SI, Johnell K, Thorslund M, et al. Trends in polypharmacy and potential drug-drug interactions across educational groups in elderly patients in Sweden for the period 1992-2002. Int J Clin Pharmacol Ther 2007:45:643-53.
17. Junius-Walker U, Theile G, Hummers-Pradier E. Prevalence and predictors of polypharmacy among older primary care patients in Germany. Fam Pract 2007;24:14-19.

18. Bradley F, Wagner AC, Elvey R, et al. Determinants of the uptake of medicines use review (MURs) by community pharmacies in England: a multi-method study. Health Policy 2008;88:258-68.

19. Dwyer LL, Han B, Woodwell DA, et al. Polypharmacy in nursing home residents in the United States: results of the 2004 National Nursing Home Survey. Am J Geriatr Pharmacother 2009;8:63-72.

20. Dong L, Yan H, Wang D. Polypharmacy and its correlates in village health clinics across 10 provinces of Western China. J Epidemiol Community Health 2010;64:549-53.

21. Catalan Health Service (CatSalut). The Catalan health care model. Health care regions. http://www10.gencat.net/catsalut/eng/coneix models.htm (accessed 17 Dec 2012).

22. Official statistics website of Catalonia (Idescat). Statistical yearbook of Catalonia. http://www.idescat.cat/pub/?id=aec\&lang=en (accessed 17 Dec 2012)

23. Classification of medicines (ATC) and defined daily doses (DDD) 2010. Helsinki: National Agency for Medicines, 2010.

24. Hovstadius B, Astrand B, Persson U, et al. Acquisition cost of dispensed drugs in individuals with multiple medications-a register-based study in Sweden. Health Policy 2011;101:153-61.

25. Farmaindustria. The pharmaceutical market in Spain. April 2009; Bulletin 48. http://www farmaindustria.es (accessed 15 Apr 2013).

26. Law 29/2006, of 26 July 2006, on guarantees and rational drug use of medicines and health products. BOE $\mathrm{n}^{\circ}$.178, of 27-07-2006; pp. 28122-65. http://www.boe.es/boe/dias/2006/07/27/pdfs/A2812228165.pdf (accessed 17 Dec 2012).

27. Royal Decree $1338 / 2006$, of 21 November 2006, developing certain aspects of the article 93 of the Law 29/2006, in the frame of the system of reference prices. BOE $n^{\circ} 279$, of 22-11-2006; pp. 4088490. http://www.boe.es/boe/dias/2006/11/22/pdfs/A40884-40890.pdf (accessed 17 Dec 2012)

28. Fernández-Liz E, Modamio $\mathrm{P}$, Catalán $\mathrm{A}$, et al. Identifying how age and gender influence prescription drug use in a primary health care environment in Catalonia, Spain. Br J Clin Pharmacol 2008;65: 407-17.

29. Clavenna A, Berti A, Gualandi L, et al. Drug utilisation profile in the Italian paediatric population. Eur J Ped 2009;168:173-81.

30. Jyrkkä J, Enlund $\mathrm{H}$, Korhonen $\mathrm{MJ}$, et al. Patterns of drug use and factors associated with polypharmacy and excessive polypharmacy in elderly persons: results of the Kuopio 75+ study: a cross-sectional analysis. Drugs Aging 2009;26:493-503.

31. Kennerfalk A, Ruigómez A, Wallander MA, et al. Geriatric drug therapy and healthcare utilization in the United Kingdom. Ann Pharmacother 2002;36:797-803.

32. Cafferata GL, Meyers SM. Pathways to psychotropic drugs. Understanding the basis of gender differences. Med Care 1990;28:285-300.

33. Simoni-Wastila L. Gender and psychotropic drug use. Med Care 1998;36:88-94.

34. Roe CM, McNamara AM, Motheral BR. Gender-and age-related prescription drug use patterns. Ann Pharmacother 2002;36:30-9.

35. Bertoldi AD, Barros AJD, Wagner A, et al. A descriptive review of the methodologies used in household surveys on medicine utilization. BMC Health Serv Res 2008;8:222-30.

36. Moen J, Norrgård S, Antonov K, et al. GP's perceptions of multiple-medicine use in older patients. J Eval Clin Pract 2010;16:69-75. 